\title{
Non-alcoholic fatty liver disease (NAFLD), metabolic syndrome and cardiovascular events in atrial fibrillation. A prospective multicenter cohort study
}

\author{
Daniele Pastori $^{1}$ (1) - Angela Sciacqua ${ }^{2} \cdot$ Rossella Marcucci $^{3} \cdot$ Maria Del Ben ${ }^{1} \cdot$ Francesco Baratta $^{1} \cdot$ Francesco Violi $^{1,4}$. \\ Pasquale Pignatelli ${ }^{1,4}$ the ATHERO-AF study group
}

Received: 22 November 2020 / Accepted: 17 February 2021 / Published online: 13 March 2021

(c) The Author(s) 2021

\begin{abstract}
Whether non-alcoholic fatty liver disease (NAFLD) is associated with an increased risk of cardiovascular events (CVEs) independently from metabolic syndrome (MetS) is still matter of debate. Aim of the study was to investigate the risk of CVEs in a high-risk population of patients with non-valvular atrial fibrillation (AF) according to the presence of MetS and NAFLD. Prospective observational multicenter study including 1,735 patients with non-valvular AF treated with vitamin $\mathrm{K}$ antagonists (VKAs) or direct oral anticoagulants (DOACs). NAFLD was defined by a fatty liver index $\geq 60$. We categorized patients in 4 groups: $0=$ neither MetS or NAFLD (38.6\%), $1=$ NAFLD alone (12.4\%), $2=$ MetS alone (19.3\%), $3=$ both MetS and NAFLD (29.7\%). Primary endpoint was a composite of CVEs. Mean age was $75.4 \pm 9.4$ years, and $41.4 \%$ of patients were women. During a mean follow-up of 34.1 \pm 22.8 months (4,926.8 patient-years), 155 CVEs were recorded (incidence rate of $3.1 \% /$ year): 55 occurred in Group 0 (2.92\%/year), 12 in Group 1 (2.17\%/year), 45 in Group 2 (4.58\%/year) and 43 in Group 3 (2.85\%/year). Multivariable Cox regression analysis showed that use of DOACs, and female sex were inversely associated with CVEs, whilst age, heart failure, previous cardiac and cerebrovascular events, and group 2 (Group 2, Hazard Ratio 1.517, 95\% Confidence Interval, 1.010-2.280) were directly associated with CVEs. In patients with AF, MetS increases the risk of CVEs. Patients with NAFLD alone have lower cardiovascular risk but may experience higher liver-related complications.
\end{abstract}

Keywords Atrial fibrillation $\cdot$ NAFLD $\cdot$ Metabolic syndrome $\cdot$ Cardiovascular events

the ATHERO-AF study group members are listed in the Acknowledgement section.

Daniele Pastori

daniele.pastori@uniroma1.it

1 I Clinica Medica, Atherothrombosis Centre, Department of Clinical Internal, Anaesthesiological and Cardiovascular Sciences, Sapienza University of Rome, Viale del Policlinico 155, 00161 Rome, Italy

2 Department of Medical and Surgical Sciences, University Magna Græcia of Catanzaro, Catanzaro, Italy

3 Department of Experimental and Clinical Medicine, University of Florence, Florence, Italy

4 Mediterranea Cardiocentro, Naples, Italy

\section{Introduction}

Patients with atrial fibrillation (AF) are characterized by a high atherosclerotic burden, as demonstrated by the high prevalence of multiple atherosclerotic risk factors, such as arterial hypertension, diabetes, obesity and dyslipidemia, accounting for an increased risk of myocardial infarction (MI) in this population [1, 2]. All these factors are usually clustered to define the metabolic syndrome (MetS) [3, 4], a condition characterized by a high risk of cardiovascular events (CVEs) [5]. Previous studies showed that MetS is highly prevalent in patients with $\mathrm{AF}$, with almost $40 \%$ of patients being affected by this condition [6]. Noteworthy, patients with $\mathrm{AF}$ and MetS disclose an increased risk of CVEs as compared to those without [7].

Non-alcoholic fatty liver disease (NAFLD) is the most common liver disease worldwide and has been long regarded as the hepatic manifestation of MetS [8]. NAFLD may range from simple steatosis to steatohepatitis carrying an increased 
risk of liver cirrhosis and hepatocellular carcinoma and representing a common indication to liver transplantation [9]. Some reports showed that patients with NAFLD have an high rate of cardiovascular comorbidities, resulting in an increased cardiovascular risk $[10,11]$. Thus, in patients with NAFLD, an increased coronary artery calcification as well as abnormalities in cardiac function have been described, leading to an increased risk of cardiac arrhythmias including AF [12]. However, not all NAFLD are of metabolic origin, and some NAFLD patients do not present with the features of MetS. The cardiovascular risk of these patients is unclear, as well as if NAFLD should be considered per se a cardiovascular risk factor (independently from MetS) is still a matter of debate.

In a recent study, we found that the prevalence of NAFLD, as assessed by the fatty liver index (FLI) was as high as $42 \%$ [13]. Despite this high prevalence, the presence of NAFLD was not associated with ischemic or bleeding risk [13].

However, the relationship of NAFLD with the presence of MetS in AF has not been investigated. In this analysis, we describe the risk of CVEs in AF patients according to the presence of NAFLD and MetS, alone or in combination.

\section{Methods}

Details of this cohort have been previously reported [13]. Briefly, 1,735 outpatients with non-valvular AF (defined by absence of mechanical prosthetic heart valve or moderate-severe mitral stenosis) on treatment with oral anticoagulants, both vitamin $\mathrm{K}$ antagonists (VKAs) and direct oral anticoagulants (DOACs) have been included in this study. Patients were recruited from three centers of internal medicine and cardiology in Rome, Catanzaro and Florence, Italy. NAFLD was diagnosed by the validated fatty liver index (FLI) with a cut-off $>60$; MetS was defined by the modified ATP-III criteria, as previously described [13].

Principal endpoint was the occurrence of CVEs, defined by a composite of fatal/non-fatal myocardial infarction or ischemic stroke, transient ischemic attack (TIA) and cardiovascular death.

\section{Statistical analysis}

Categorical variables were reported as counts (percentages). The normal distribution of parameters was assessed by Kolmogorov-Smirnov test. Continuous variables were expressed as mean \pm standard deviation. Student $t$ test for unpaired samples was used to compare means. Independence of categorical variables was tested with the $\chi^{2}$ test.
Patients were divided into four groups as follows: $0=$ neither MetS nor NAFLD, $1=$ NAFLD alone, $2=$ MetS alone, $3=$ both MetS and NAFLD. Characteristics of patients according to each study group have been described. Univariate and multivariate Cox proportional hazards regression analysis was used to calculate the relative adjusted hazard ratio (HR) and 95\% confidence interval (CI) for CVEs by each clinical variable. In addition to the four study groups, the following covariates were entered in the multivariable model: type of oral anticoagulant (DOAC vs VKAs), persistent/permanent AF (vs paroxysmal), sex, age (continuous), current cigarette smoking, heart failure (HF), previous cardiac and cerebrovascular events, eGFR, antiplatelet drug, statin, digoxin. Arterial hypertension, diabetes and obesity indices were not included as already present in the MetS and FLI variables.

Statistical significance was set at a $p$ value $<0.05$. All tests were two-tailed and analyses were performed using computer software packages (SPSS-25.0, SPSS Inc.).

The study protocol was approved by the local ethical board of Sapienza-University of Rome and was conducted according to the principles of the Declaration of Helsinki.

\section{Results}

Overall, 669 (38.6\%) AF patients were not diagnosed with MetS or NAFLD (Group 0), 216 (12.4\%) had NAFLD alone (without MetS, Group 1) and 334 (19.3\%) had MetS alone (without NAFLD, Group 2). MetS and NAFLD coexisted in $516(29.7 \%)$ of patients (Group 3). Table 1 reports clinical and biochemical characteristics of each group. The group of patients with NAFLD alone disclosed the lowest proportion of women, and a low prevalence of cardiovascular risk factors, such as hypertension, diabetes and heart failure; conversely, these patients presented with elevated values of GGT (Table 1). Patients with MetS showed the highest mean age and proportion of women, while they were less likely to be treated with DOACs (Table 1).

Patients with MetS and NAFLD were more frequently affected by persistent/permanent $\mathrm{AF}$, with the highest degree of obesity and prevalence of diabetes compared to the other groups (Table 1). Nearly half of the patients in groups 2 and 3 was on treatment with statins.

\section{Cardiovascular events}

During a mean follow-up of $34.1 \pm 22.8$ months $(4,926.8$ patient-years), 155 CVEs were recorded with an incidence rate (IR) of 3.15\%/year (95\% CI 2.67-3.68): 55 occurred in Group 0 (2.92\%/year, 95\% CI 2.20-3.80), 12 in Group 1 
Table 1 Clinical and biochemical characteristics of atrial fibrillation patients according to the presence of metabolic syndrome and NAFLD

\begin{tabular}{|c|c|c|c|c|c|c|c|c|c|}
\hline & $\begin{array}{l}\text { Group } 0 \text { (No } \\
\text { MetS, No } \\
\text { NAFLD) } \\
n=669\end{array}$ & $\begin{array}{l}\text { Group 1 } \\
\text { (NAFLD } \\
\text { alone) } \\
\mathrm{n}=216\end{array}$ & $\begin{array}{l}p \text { value (1 } \\
\text { vs group } 0 \text { ) }\end{array}$ & $\begin{array}{l}\text { Group } 2 \\
\text { (MetS alone) } \\
n=334\end{array}$ & $\begin{array}{l}p \text { value }(2 \\
\text { vs group } 0 \text { ) }\end{array}$ & $\begin{array}{l}p \text { value (2 } \\
\text { vs group 1) }\end{array}$ & $\begin{array}{l}\text { Group } 3 \\
\text { (MetS + NAFLD) } \\
n=516\end{array}$ & $\begin{array}{l}p \text { value (3 } \\
\text { vs group } 0 \text { ) }\end{array}$ & $\begin{array}{l}p \text { value } \\
\text { (among } \\
\text { groups) }\end{array}$ \\
\hline Age (years) & $75.4 \pm 9.4$ & $73.5 \pm 9.9$ & 0.010 & $76.2 \pm 8.1$ & 0.186 & 0.001 & $73.8 \pm 8.7$ & 0.004 & $<0.001$ \\
\hline Women (\%) & 41.4 & 23.1 & $<0.001$ & 63.8 & $<0.001$ & $<0.001$ & 42.8 & 0.635 & $<0.001$ \\
\hline $\begin{array}{l}\text { DOAC (vs. } \\
\text { VKA) (\%) }\end{array}$ & 57.2 & 64.8 & 0.056 & 54.5 & 0.418 & 0.017 & 62.6 & 0.065 & 0.024 \\
\hline $\begin{array}{l}\text { Persistent/ } \\
\text { permanent } \\
\text { AF }(\%)\end{array}$ & 53.4 & 56.9 & 0.388 & 62.0 & 0.010 & 0.248 & 65.7 & $<0.001$ & $<0.001$ \\
\hline $\begin{array}{l}\text { Body Mass } \\
\text { Index }(\mathrm{Kg} / \\
\left.\mathrm{m}^{2}\right)\end{array}$ & $24.2 \pm 2.9$ & $29.7 \pm 4.1$ & $<0.001$ & $25.6 \pm 2.4$ & $<0.001$ & $<0.001$ & $31.3 \pm 4.2$ & $<0.001$ & $<0.001$ \\
\hline $\begin{array}{l}\text { Waist cir- } \\
\text { cumference } \\
(\mathrm{cm})\end{array}$ & $91.8 \pm 8.4$ & $107.3 \pm 9.9$ & $<0.001$ & $95.2 \pm 7.4$ & $<0.001$ & $<0.001$ & $110.1 \pm 9.8$ & $<0.001$ & $<0.001$ \\
\hline GGT (U/l) & $29.5 \pm 19.4$ & $51.9 \pm 39.5$ & $<0.001$ & $25.9 \pm 15.2$ & 0.040 & $<0.001$ & $43.9 \pm 33.3$ & $<0.001$ & $<0.001$ \\
\hline $\begin{array}{l}\text { Triglycerides } \\
(\mathrm{mg} / \mathrm{dl})\end{array}$ & $98.3 \pm 36.7$ & $119.4 \pm 50.2$ & $<0.001$ & $116.1 \pm 49.4$ & $<0.001$ & 0.504 & $161.5 \pm 80.6$ & $<0.001$ & $<0.001$ \\
\hline $\begin{array}{l}\text { Total choles- } \\
\text { terol (mg/ } \\
\text { dl) }\end{array}$ & $182.4 \pm 43.0$ & $193.4 \pm 44.5$ & 0.003 & $173.4 \pm 47.4$ & 0.004 & $<0,001$ & $186.1 \pm 52.4$ & 0.175 & $<0.001$ \\
\hline HDL (mg/dl) & $53.8 \pm 15.8$ & $54.4 \pm 16.4$ & 0.629 & $44.0 \pm 15.1$ & $<0.001$ & $<0.001$ & $45.0 \pm 16.4$ & $<0.001$ & $<0.001$ \\
\hline LDL (mg/dl) & $109.4 \pm 37.3$ & $116.4 \pm 42.6$ & 0.030 & $106.9 \pm 41.2$ & 0.379 & 0.009 & $111.4 \pm 45.2$ & 0.398 & 0.054 \\
\hline $\begin{array}{l}\text { Current } \\
\text { smoking } \\
(\%)\end{array}$ & 7.9 & 7.9 & 0.980 & 9.9 & 0.338 & 0.452 & 10.5 & 0.152 & 0.402 \\
\hline $\begin{array}{l}\mathrm{GFR}(\mathrm{ml} / \\
\mathrm{min} / 1.73 \\
\left.\mathrm{~m}^{2}\right)\end{array}$ & $75.9 \pm 22.5$ & $75.2 \pm 20.8$ & 0.689 & $71.4 \pm 22.6$ & 0.003 & 0.053 & $72.1 \pm 22.4$ & 0.003 & 0.003 \\
\hline $\begin{array}{l}\text { HAS-BLED } \\
\text { score }\end{array}$ & $1.6 \pm 0.9$ & $1.6 \pm 0.8$ & 0.556 & $1.6 \pm 0.9$ & 0.791 & 0.746 & $1.5 \pm 0.9$ & 0.057 & 0.277 \\
\hline $\begin{array}{l}\mathrm{CHA}_{2} \mathrm{DS}_{2} \\
\text { VASc score }\end{array}$ & $3.4 \pm 1.5$ & $3.1 \pm 1.4$ & 0.114 & $4.3 \pm 1.4$ & 0.098 & 0.127 & $3.8 \pm 1.5$ & 0.085 & $<0.001$ \\
\hline $\begin{array}{l}\text { Arterial } \\
\text { Hyperten- } \\
\text { sion }(\%)\end{array}$ & 78.6 & 80.6 & 0.565 & 98.2 & $<0.001$ & $<0.001$ & 95.9 & $<0.001$ & $<0.001$ \\
\hline Diabetes (\%) & 9.3 & 7.4 & 0.490 & 35.6 & $<0.001$ & $<0.001$ & 41.1 & $<0.001$ & $<0.001$ \\
\hline $\begin{array}{l}\text { Heart failure } \\
(\%)\end{array}$ & 14.8 & 12.0 & 0.369 & 20.4 & 0.031 & 0.015 & 17.8 & 0.176 & 0.032 \\
\hline $\begin{array}{l}\text { Previous } \\
\text { cerebrovas- } \\
\text { cular events } \\
(\%)\end{array}$ & 14.9 & 15.7 & 0.827 & 19.2 & 0.103 & 0.361 & 17.8 & 0.203 & 0.315 \\
\hline $\begin{array}{l}\text { Previous car- } \\
\text { diac events } \\
(\%)\end{array}$ & 16.0 & 20.8 & 0.119 & 24.3 & 0.002 & 0.406 & 21.5 & 0.016 & 0.010 \\
\hline $\begin{array}{c}\text { Antiplatelet } \\
\text { drugs (\%) }\end{array}$ & 12.0 & 16.2 & 0.130 & 11.4 & 0.836 & 0.122 & 12.4 & 0.858 & 0.351 \\
\hline Insulin (\%) & 1.2 & 1.9 & 0.469 & 6.3 & $<0.001$ & 0.019 & 9.1 & $<0.001$ & $<0.001$ \\
\hline Statins (\%) & 38.9 & 39.8 & 0.810 & 49.4 & 0.002 & 0.029 & 51.6 & $<0.001$ & $<0.001$ \\
\hline Digoxin (\%) & 16.7 & 14.4 & 0.457 & 17.7 & 0.722 & 0.346 & 15.3 & 0.525 & 0.678 \\
\hline
\end{tabular}

$A F$ atrial fibrillation, $D O A C$ direct oral anticoagulants, $G F R$ glomerular filtration rate, $G G T$ gamma-glutamyl transpeptidase, $H D L$ high-density lipoprotein, $L D L$ low-density lipoprotein, MetS metabolic syndrome, NAFLD non-alcoholic fatty liver disease, VKA vitamin K antagonist 
Fig. 1 Univariate hazard ratio by each group for cardiovascular events

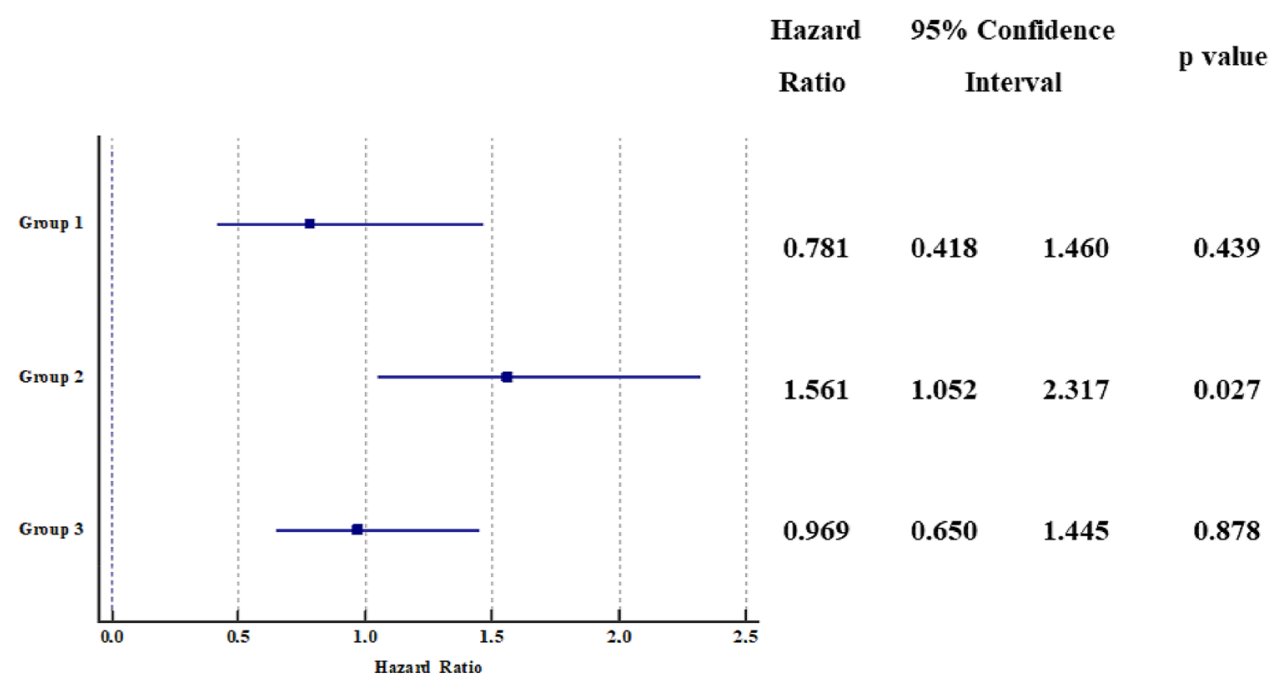

Table 2 Cox proportional hazard regression analysis of factors associated with cardiovascular events

\begin{tabular}{|c|c|c|c|c|}
\hline \multirow[b]{2}{*}{ DOACs (vs VKAs) } & \multirow{2}{*}{$\begin{array}{l}p \text { value } \\
0.012\end{array}$} & \multirow{2}{*}{$\begin{array}{l}\text { Hazard ratio } \\
0.621\end{array}$} & \multicolumn{2}{|c|}{$\begin{array}{l}95 \% \\
\text { confidence } \\
\text { interval }\end{array}$} \\
\hline & & & 0.428 & 0.901 \\
\hline Persistent/permanent AF & 0.410 & 0.868 & 0.620 & 1.215 \\
\hline Female sex & 0.009 & 0.623 & 0.437 & 0.889 \\
\hline Age (continuous) & 0.000 & 1.064 & 1.039 & 1.090 \\
\hline Current cigarette smoking & 0.063 & 1.606 & 0.975 & 2.644 \\
\hline Heart Failure & 0.004 & 1.727 & 1.189 & 2.507 \\
\hline Previous cardiac events & 0.008 & 1.658 & 1.143 & 2.406 \\
\hline $\begin{array}{l}\text { Previous cerebrovascular } \\
\text { events }\end{array}$ & 0.000 & 2.224 & 1.546 & 3.200 \\
\hline GFR (continuous) & 0.145 & 1.005 & 0.998 & 1.012 \\
\hline Antiplatelet drugs & 0.500 & 1.168 & 0.745 & 1.831 \\
\hline Group 1 (NAFLD alone)* & 0.890 & 0.956 & 0.504 & 1.811 \\
\hline Group 2 (MetS alone)* & 0.045 & 1.517 & 1.010 & 2.280 \\
\hline Group 3 (NAFLD + MetS)* & 0.551 & 1.133 & 0.751 & 1.709 \\
\hline Statins & 0.388 & 0.862 & 0.616 & 1.207 \\
\hline Digoxin & 0.193 & 1.298 & 0.876 & 1.922 \\
\hline
\end{tabular}

$A F$ atrial fibrillation, DOACs direct oral anticoagulants, GFR glomerular filtration rate, MetS metabolic syndrome, NAFLD non-alcoholic fatty liver disease, $V K A$ vitamin $\mathrm{K}$ antagonist

* Group 0 (No MetS, no NAFLD) as reference group. Global $p$ value $p=0.209$

(2.17\%/year, 95\% CI 1.12-3.79, $\mathrm{p}=0.352$ vs. group 0$), 45$ in Group 2 (4.58\%/year, 95\% CI 3.34-6.13, $p=0.024$ vs. group 0) and 43 in Group 3 (2.85\%/year, 95\% CI 2.06-3.84, $p=0.909$ vs. group 0). Figure 1 shows univariate HR by each study group. At multivariable Cox proportional hazard regression analysis (Table 2), we found that use of DOACs (vs VKAs), and female sex were inversely associated with the risk of CVEs, whilst age, heart failure, previous cardiac and cerebrovascular events, and group 2 (MetS alone) were directly associated with CVEs. This was also displayed by adjusted survival curves (Fig. 2), showing a decreased survival for group 2 compared to other groups.

\section{Discussion}

Our study shows that the cardiovascular risk in patients with AF seems to be driven by the presence of MetS, while the coexistence of NAFLD does not seem to modify the association with CVEs.

The relationship between NAFLD, with or without MetS, and cardiovascular risk has been studied in few previous works in non-AF patients. Younossi et al. in a cohort of 6,709 patients from the National Health and Nutrition Examination Survey III (NHANES III) database, of whom 1,448 with hepatic steatosis at ultrasound, analyzed the relationship between NAFLD and CVEs. The age of patients was relatively young with a mean age of 50 years; the majority of NAFLD patients (78.9\%) had also MetS. In patients who presented with association of NAFLD and MetS, the risk of total $(p<0.001)$, and cardiovascular mortality $(\mathrm{p}<0.001)$, was increased [14]. This result was not evident in patients with NAFLD alone [14].

A study by Karajamaki et al. that included 958 middleaged people, showed that the risk of CVEs was higher in patients with MetS, with or without NAFLD [15].

However, all these studies were performed in a middleaged population, at low cardiovascular risk and not affected by AF. Our study included a population of elderly patients with a mean age of 75 years, characterized by a high prevalence of cardio-metabolic diseases, such hypertension, diabetes and obesity.

The clinical phenotype of patients with NAFLD alone in our study, characterized by a lower prevalence of 
Fig. 2 Adjusted cumulative survival curves according to each study group

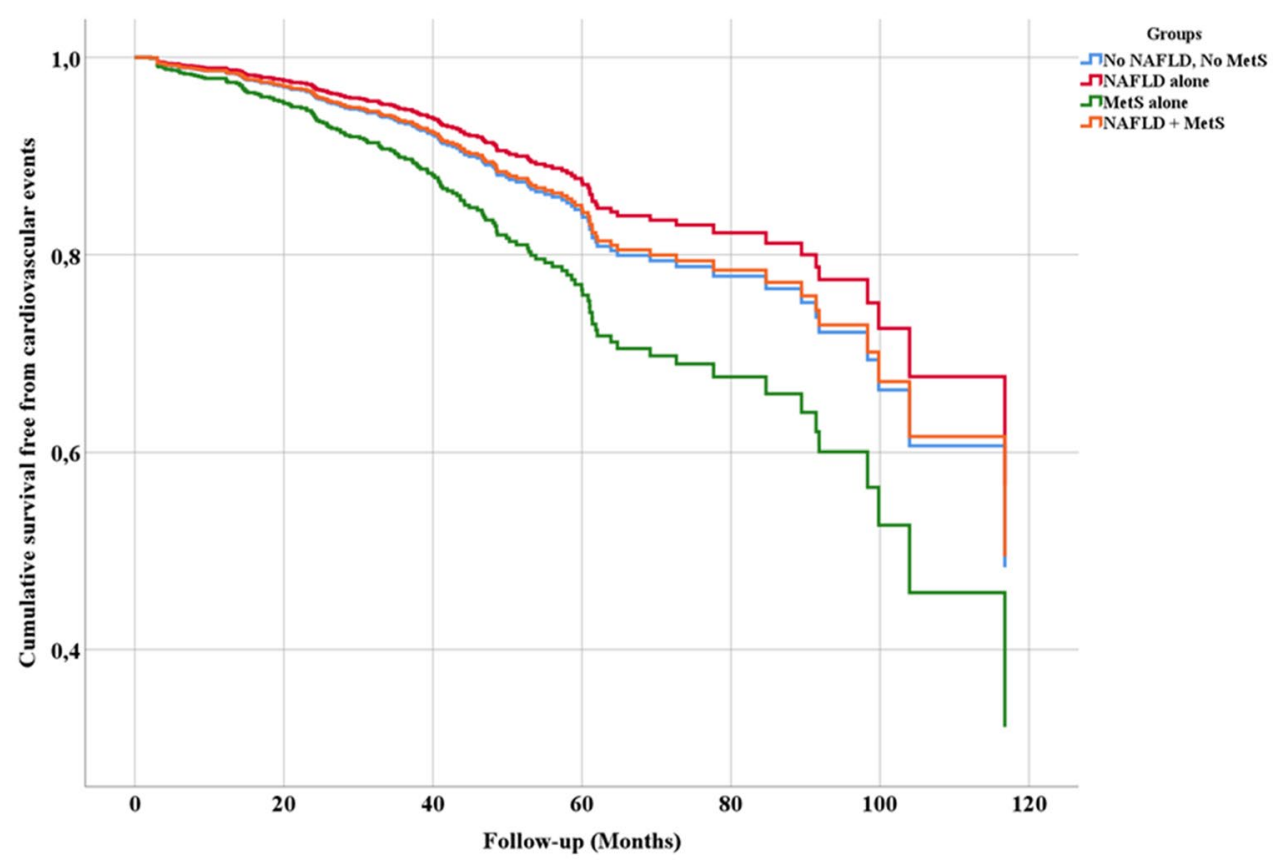

cardiovascular comorbidities, lower use of insulin, and high GGT values, suggest that these patients may have a liver steatosis not strictly correlated to metabolic abnormalities, but rather to a genetic predisposition. These patients may benefit from a genetic screening for PNPLA3 mutation, to identify those with a more aggressive disease and at higher risk of progression to liver cirrhosis [16]. Furthermore, patients with NAFLD alone were less likely to be women, confirming a high prevalence of NAFLD in males than females also in AF patients [4]. A longer follow-up will clarify if this group of patients will experience more liver-related complications than CVEs compared to those affected by MetS.

The data of our work also demonstrates in a population affected by AF that the relationship between metabolic diseases and cardiovascular risk is strongly linked to the presence of MetS, rather than to NAFLD itself. This result highlights the need for a comprehensive management of patients with AF, which should consist in addressing potential modifiable risk factors, such as obesity, and in reaching optimal guideline-recommended targets for blood pressure and glucose control. Thus, in patients with AF, an optimal management of comorbidities according to the Atrial fibrillation Better Care (ABC) pathway (A, Avoid stroke with anticoagulation; $\mathrm{B}$, better symptom management; $\mathrm{C}$, Cardiovascular and comorbidity risk management) resulted in a lower CVEs incidence $[17,18]$.

Another interesting result of our study is that the treatment with DOAC, compared to VKA, is associated with a reduction of the risk of cardiovascular events. Of note, the use of DOACs was lower in patients with MetS, which may depend on the fact that the use of DOAC in morbid obese patients is still uncertain [19].

Limitations of the study include enrollment of elderly Caucasian patients only, so the application of these data to patients of other ethnicities is uncertain. Furthermore, the observational study design does not allow to establish a cause-effect relationship between the studied variables and the observed endpoints. However, results come from a multicenter prospective study with a structured follow-up. Another limitations is represented by the lack of data on blood glucose control, which may affect cardiovascular risk.

In conclusion, in patients with AF, MetS seems to be the main factor leading to incident CVEs, independently from the presence of NAFLD. Patients with NAFLD alone showed lower cardiovascular risk, but a longer follow-up will clarify if these patients are more likely to experience liver-related complications than CVEs.

Acknowledgements ATHERO-AF study group members: Mirella Saliola, Danilo Menichelli, Marco Antonio Casciaro, Francesco Angelico, Vittoria Cammisotto, Cristina Nocella, Simona Bartimoccia, Roberto Carnevale, Laura Novelli.

Author contribution DP, FV, PP study concept and design; DP statistical analysis; DP, AS, RM, MDB, FB, FV, PP acquisition of data; analysis and interpretation of data; DP, AS, RM, MDB, FB, FV, PP drafting of the manuscript; critical revision of the manuscript for important intellectual content; study supervision.

Funding Open access funding provided by Università degli Studi di Roma La Sapienza within the CRUI-CARE Agreement. 


\section{Compliance with ethical standards}

Conflict of interest The authors have nothing to disclose.

Ethical approval The study was approved by the local ethical board of Sapienza University of Rome and by the ethical committees of each participating center.

Human and animal rights All procedures performed in studies involving human participants were in accordance with the ethical standards of the institutional and/or national research committee and with the 1964 Helsinki declaration and its later amendments or comparable ethical standards.

Informed consent Informed consent was obtained from all individual participants included in the study.

Open Access This article is licensed under a Creative Commons Attribution 4.0 International License, which permits use, sharing, adaptation, distribution and reproduction in any medium or format, as long as you give appropriate credit to the original author(s) and the source, provide a link to the Creative Commons licence, and indicate if changes were made. The images or other third party material in this article are included in the article's Creative Commons licence, unless indicated otherwise in a credit line to the material. If material is not included in the article's Creative Commons licence and your intended use is not permitted by statutory regulation or exceeds the permitted use, you will need to obtain permission directly from the copyright holder. To view a copy of this licence, visit http://creativecommons.org/licenses/by/4.0/.

\section{References}

1. Violi F, Soliman EZ, Pignatelli P, Pastori D (2016) Atrial fibrillation and myocardial infarction: a systematic review and appraisal of pathophysiologic mechanisms. J Am Heart Assoc. https://doi. org/10.1161/JAHA.116.003347.

2. Soliman EZ, Safford MM, Muntner P, Khodneva Y, Dawood FZ, Zakai NA et al (2014) Atrial fibrillation and the risk of myocardial infarction. JAMA Internal Med 174(1):107-114. https://doi.org/ 10.1001/jamainternmed.2013.11912

3. Alberti KG, Eckel RH, Grundy SM, Zimmet PZ, Cleeman JI, Donato KA et al (2009) Harmonizing the metabolic syndrome: a joint interim statement of the International Diabetes Federation Task Force on Epidemiology and Prevention; National Heart, Lung, and Blood Institute; American Heart Association; World Heart Federation; International Atherosclerosis Society; and International Association for the Study of Obesity. Circulation 120(16):1640-1645. https://doi.org/10.1161/CIRCULATIO NAHA.109.192644

4. Santilli F, D'Ardes D, Guagnano MT, Davi G (2017) Metabolic syndrome: sex-related cardiovascular risk and therapeutic approach. Curr Med Chem 24(24):2602-2627. https://doi.org/10. 2174/0929867324666170710121145

5. Riahi SM, Moamer S, Namdari M, Mokhayeri Y, Pourhoseingholi MA, Hashemi-Nazari SS (2018) Patterns of clustering of the metabolic syndrome components and its association with coronary heart disease in the Multi-Ethnic Study of Atherosclerosis (MESA): A latent class analysis. Int J Cardiol 271:13-18. https:// doi.org/10.1016/j.ijcard.2018.05.080

6. Pastori D, Pignatelli P, Angelico F, Farcomeni A, Del Ben M, Vicario $T$ et al (2015) Incidence of myocardial infarction and vascular death in elderly patients with atrial fibrillation taking anticoagulants: relation to atherosclerotic risk factors. Chest 147(6):1644-1650. https://doi.org/10.1378/chest.14-2414

7. Polovina M, Hindricks G, Maggioni A, Piepoli M, Vardas P, Asanin M et al (2018) Association of metabolic syndrome with non-thromboembolic adverse cardiac outcomes in patients with atrial fibrillation. Eur Heart J 39(45):4030-4039. https://doi.org/ 10.1093/eurheartj/ehy446

8. Angelico F, Del Ben M, Conti R, Francioso S, Feole K, Maccioni $D$ et al (2003) Non-alcoholic fatty liver syndrome: a hepatic consequence of common metabolic diseases. J Gastroenterol Hepatol 18(5):588-594

9. Khan RS, Newsome PN (2016) Non-alcoholic fatty liver disease and liver transplantation. Metab Clin Exp 65(8):1208-23. https:// doi.org/10.1016/j.metabol.2016.02.013

10. Hamaguchi M, Kojima T, Takeda N, Nagata C, Takeda J, Sarui $\mathrm{H}$ et al (2007) Nonalcoholic fatty liver disease is a novel predictor of cardiovascular disease. World J Gastroenterol WJG 13(10):1579-1584

11. Gaudio E, Nobili V, Franchitto A, Onori P, Carpino G (2012) Nonalcoholic fatty liver disease and atherosclerosis. Intern Emerg Med 7(Suppl 3):S297-305. https://doi.org/10.1007/s11739-012-0826-5

12. Anstee QM, Mantovani A, Tilg H, Targher G (2018) Risk of cardiomyopathy and cardiac arrhythmias in patients with nonalcoholic fatty liver disease. Nat Rev Gastroenterol Hepatol. https://doi.org/ 10.1038/s41575-018-0010-0

13. Pastori D, Sciacqua A, Marcucci R, Farcomeni A, Perticone F, Del Ben $M$ et al (2019) Prevalence and impact of nonalcoholic fatty liver disease in atrial fibrillation. Mayo Clin Proc. https://doi.org/ 10.1016/j.mayocp.2019.08.027

14. Younossi ZM, Otgonsuren M, Venkatesan C, Mishra A (2013) In patients with non-alcoholic fatty liver disease, metabolically abnormal individuals are at a higher risk for mortality while metabolically normal individuals are not. Metab Clin Exp 62(3):35260. https://doi.org/10.1016/j.metabol.2012.08.005

15. Karajamaki AJ, Bloigu R, Kauma H, Kesaniemi YA, Koivurova OP, Perkiomaki J et al (2017) Non-alcoholic fatty liver disease with and without metabolic syndrome: Different long-term outcomes. Metab Clin Exp 66:55-63. https://doi.org/10.1016/j.metab ol.2016.06.009

16. Valenti L, Al-Serri A, Daly AK, Galmozzi E, Rametta R, Dongiovanni $P$ et al (2010) Homozygosity for the patatin-like phospholipase-3/adiponutrin I148M polymorphism influences liver fibrosis in patients with nonalcoholic fatty liver disease. Hepatology 51(4):1209-1217. https://doi.org/10.1002/hep.23622

17. Pastori D, Pignatelli P, Menichelli D, Violi F, Lip GYH (2019) Integrated care management of patients with atrial fibrillation and risk of cardiovascular events: the $\mathrm{ABC}$ (Atrial fibrillation Better Care) pathway in the ATHERO-AF Study Cohort. Mayo Clin Proc 94(7):1261-1267. https://doi.org/10.1016/j.mayocp.2018.10.022

18. Pastori D, Farcomeni A, Pignatelli P, Violi F, Lip GY (2019) $\mathrm{ABC}$ (Atrial fibrillation Better Care) pathway and healthcare costs in atrial fibrillation: The ATHERO-AF study. Am J Med 132(7):856-861. https://doi.org/10.1016/j.amjmed.2019.01.003

19. Menichelli D, Ettorre E, Pani A, Violi F, Pignatelli P, Pastori D (2019) Update and unmet needs on the use of nonvitamin K oral anticoagulants for stroke prevention in patients with atrial fibrillation. Curr Probl Cardiol. https://doi.org/10.1016/j.cpcardiol.2019. 02.002

Publisher's Note Springer Nature remains neutral with regard to jurisdictional claims in published maps and institutional affiliations. 